BENTHAM OPEN
CrossMark
Content list available at: www.benthamopen.com/TODENTJ/
DOI: $10.2174 / 1874210601610010431$

RESEARCH ARTICLE

\title{
Color Stability of Composites After Short-term Oral Simulation: An in vitro Study
}

Didem Öner Özdaş ${ }^{\mathrm{a}}$, Mağrur Kazak ${ }^{\mathrm{b}}$, Aylin Çilingir ${ }^{\mathrm{c}}$, Meryem Gülce Subaşı, ${ }^{\mathrm{d},{ }^{*}}$, Murat Tiryaki ${ }^{\mathrm{e}}$ and Şölen Günal ${ }^{\mathrm{f}}$

${ }^{a}$ Department of Pedodontics, Faculty of Dentistry, İstanbul Aydin University, İstanbul, Turkey

${ }^{b}$ Department of Restorative Dentistry, Faculty of Dentistry, İstanbul Aydin University, İstanbul, Turkey

${ }^{c}$ Department of Restorative Dentistry, Faculty of Dentistry, Trakya University, Edirne, Turkey

${ }^{d}$ Department of Prosthodontics, Faculty of Dentistry, İstanbul Aydin University, İstanbul, Turkey

${ }^{e}$ Department of Restorative Dentistry, Faculty of Dentistry, Istanbul University, Istanbul, Turkey

${ }^{f}$ Department of Restorative Dentistry, Faculty of Dentistry, İstanbul Kemerburgaz University, İstanbul, Turkey

Received: November 29, 2015

Revised: June 22, 2016

Accepted: July 12, 2016

Abstract:

\section{Background:}

Although most of the studies investigated color stability of different restorative materials, evaluation of color stability of composites after immersion in multiple beverages in the same day by an in vitro oral simulation study is unclear.

\section{Objective:}

To assess color change of different restorative materials at the end of days 1, 14, and 30 of immersion in multiple liquid types to mimic the oral environment in vitro.

\section{Method:}

Ten disc-shaped specimens were made from each of four different resin composites (Filtek Z250, Voco x-tra base, Beautifil Flow Plus, Beautifil II). Baseline color value of each sample was measured using a spectrophotometer. Each composite was respectively immersed in coffee, an orange/pomegranate juice mixture, black tea, and a mouth rinse on the same day to mimic daily liquid consumption of individuals. Color measurements were taken after 1, 14, and 30 days by spectrophotometer and color change values were calculated. Statistical analyses were executed by one-way ANOVA/Tukey HSD and repeated-measures ANOVA.

\section{Results:}

All materials showed significant color change after 1,14 , and 30 days $(P<0.01)$ of immersion in liquids, with the lowest color alteration observed at the $1^{\text {st }}$ day and the highest observed after the $30^{\text {th }}$ day. Among the materials tested, at each time point $(1,14$, and 30 days), the lowest color alteration was detected in Filtek Z250 and the highest color alteration was detected in Beautifil II.

\section{Conclusion:}

Color alteration of composite resins is affected by composite type and storage time. With the exception of 1 day of storage, color changes of all materials were substantial and clinically unacceptable.

Keywords: Beverage type, Color alteration, Color measurement, Composite resin, Oral simulation, Storage time.

\footnotetext{
* Address correspondence to this author at the Department of Prosthodontics, Faculty of Dentistry, İstanbul Aydın University, İstanbul, Turkey; Tel: +90212448347/29533; Fax: +902125556191; E-mail: gulce2subasi@yahoo.co.uk
} 


\section{INTRODUCTION}

Composite resins are used in direct/indirect restorations and for the intraoral repair of porcelain restorations to modify the tooth contour and color. The success of an esthetic restoration bases primarily on the color consistency and on the color stability of the material [1].

Staining or discoloration of the restorative material is one of the reasons for replacement of composite restorations, which occurs because of the aging process in the oral environment [2] induced by several extrinsic or intrinsic factors. Extrinsic factors can differ according to the individual's nutrition, and smoking habits [3 - 6]. Intrinsic factors include discoloration of the resin material and depend on the resin matrix, filler weight, particle size distribution, and type of photoinititiator $[7,8]$.

In the literature the effect of beverage type $[4,5,9]$ and storage time $[10,11]$ on the color stability of restorative materials was investigated. Some studies [12 - 15] investigated the color stability of different restorative materials by testing them both in artificial saliva and beverages in different periods to mimic the oral environment in vitro. In these studies [12 - 15] the color change evalution of composite after each beverage immersion was determined separately from other beverages. Therefore, to more accurately mimic the oral environment in vitro, which is naturally exposed to various types of substances throughout the day, in the current study, we investigated the color stability over 30 days of four typical restorative materials that were exposed to multiple types of liquids on the same day. The tested null hypotheses were that (1) the type of composite resin does not affect the color stability of the restorative material, and (2) the overall exposure time in the liquids $(1,14$, or 30 days) does not affect the color stability of the composite restorative material.

\section{MATERIALS AND METHODOLOGY}

\section{Composite Specimen Preparation}

Prior to carrying out the experiment, a power analysis was performed to identify the sample number required to accurately detect significant effects. Based on the power analysis, 10 circular-shaped samples (diameter: $10 \mathrm{~mm}$, thickness: $2 \mathrm{~mm}$ ) were prepared from each of four composite resins in A2 shade using a cylindrical teflon mold: Filtek Z250 (3M ESPE; St. Paul, MN, USA), Voco x-tra Base (Voco GmbH; Cuxhaven, Germany), Beautifil II (Shofu Inc.; Kyoto, Japan), and Beautifil Flow Plus (Shofu Inc.; Kyoto, Japan). The compositions of the restorative materials used are provided in Table 1. In the Voco x-tra Base group, the composite was injected directly in the mold, whereas the other composites were prepared according to the incremental technique. The last portion of the composite was covered with a glass to get a plane surface. Then, the composites were light polymerized for $20 \mathrm{~s}$ from the upper and lower surfaces using an LED light-curing unit (Elipar S10; 3M ESPE; St. Paul, MN, USA) at a light intensity of 1200 $\mathrm{mW} / \mathrm{cm}^{2}$ and a wavelength of 430-480 nm. During the polymerization, the tip of the light-curing device was positioned perpendicular to the sample surface. After polymerization, the upper surfaces of all samples were finished with medium, fine, and super-fine discs (Sof-Lex, 3M ESPE; St. Paul, MN, USA) for $30 \mathrm{~s}$ using a slow-speed hand piece. After each polishing step, each polishing disc was discarded and the samples were thoroughly rinsed with water for $10 \mathrm{~s}$ and airdried for $5 \mathrm{~s}$. All samples were kept in distilled water at $37^{\circ} \mathrm{C}$ for $24 \mathrm{~h}$ in an incubator (Star Dental 320S; İstanbul, Turkey).

Table 1. Contents of the resin composite materials.

\begin{tabular}{|c|c|c|c|c|c|c|}
\hline \multirow[b]{2}{*}{ Resin composite } & \multirow[b]{2}{*}{ Classification } & \multicolumn{3}{|l|}{ Filler } & \multirow[b]{2}{*}{ Resin Matrix } & \multirow[b]{2}{*}{$\begin{array}{l}\text { Shade/Lot } \\
\text { Number }\end{array}$} \\
\hline & & Type & $\begin{array}{c}\text { Volume } \\
(\%)\end{array}$ & Size & & \\
\hline $\begin{array}{l}\text { Filtek Z250 } \\
\text { (3M Espe, St Paul, } \\
\text { MN, USA) }\end{array}$ & Minifilled hybrid & Zirconia/Silica & 60 & $\begin{array}{l}0.6 \\
\mu \mathrm{m}\end{array}$ & $\begin{array}{l}\text { Bis-EMA, } \\
\text { UDMA, } \\
\text { Bis-GMA }\end{array}$ & A2/N439013 \\
\hline $\begin{array}{c}\text { Voco x-tra Base } \\
\text { (Voco GmbH, } \\
\text { Cuxhaven, } \\
\text { Germany) }\end{array}$ & Flowable Bulk-Fill & Silica & 58 & & Bis-EMA, MMA & A2/1335117 \\
\hline $\begin{array}{l}\text { Beautifil Flow Plus } \\
\text { (Shofu Inc., Kyoto, } \\
\text { Japan) }\end{array}$ & $\begin{array}{c}\text { Fluoride-releasing flowable } \\
\text { hybrid composite }\end{array}$ & $\begin{array}{c}\text { Multi-functional glass filler, S-PRG } \\
\text { filler based on fluoroboroaluminosilicate } \\
\text { glass }\end{array}$ & 47 & $\begin{array}{l}0.8 \\
\mu \mathrm{m}\end{array}$ & $\begin{array}{l}\text { Bis-GMA, } \\
\text { TEGDMA }\end{array}$ & $\mathrm{A} 2 / 071350$ \\
\hline
\end{tabular}




\begin{tabular}{|c|c|c|c|c|c|c|}
\hline \multirow[b]{2}{*}{ Resin composite } & \multirow[b]{2}{*}{ Classification } & \multicolumn{3}{|l|}{ Filler } & \multirow[b]{2}{*}{ Resin Matrix } & \multirow{2}{*}{$\begin{array}{c}\text { Shade/Lot } \\
\text { Number }\end{array}$} \\
\hline & & Type & $\begin{array}{c}\text { Volume } \\
(\%)\end{array}$ & Size & & \\
\hline $\begin{array}{c}\text { Beautifil II } \\
\text { (Shofu Inc., Kyoto, } \\
\text { Japan) }\end{array}$ & $\begin{array}{l}\text { Fluoride releasing nano- } \\
\text { hybrid composite }\end{array}$ & $\begin{array}{c}\text { Multi-Functional glass filler and S-PRG } \\
\text { filler based on fluoroboroaluminosilicate } \\
\text { glass }\end{array}$ & 68.6 & $\begin{array}{l}0.8 \\
\mu \mathrm{m}\end{array}$ & $\begin{array}{l}\text { Bis-GMA, } \\
\text { TEGDMA }\end{array}$ & A2/111268 \\
\hline
\end{tabular}

Bis-EMA: Ethoxylated bisphenol-A glycol dimethacrylate; UDMA: urethane dimethacrylate; Bis-GMA: Bisphenol A glycol dimethacrylate; MMA: methylmethacrylate; TEGDMA: Triethylene glycol dimethacrylate; S-PRG: Surface pre-reacted glass.

\section{Immersion of Specimens in Liquids}

To mimic the daily consumption of a person, after $24 \mathrm{~h}$ of incubation, each of the composite resin specimens $(\mathrm{n}=10$ per group) was individually immersed in flasks containing $5 \mathrm{~mL}$ coffee (Nescafe Classic, Nestle Suisse, Vevey, Switzerland) (pH 5.45) at 9:00 for $15 \mathrm{~min}, 5 \mathrm{~mL}$ of a juice mixture ( $2.5 \mathrm{~mL}$ orange juice and $2.5 \mathrm{~mL}$ pomegranate juice) (Cappy, Bursa, Turkey) (pH 3.84) at 12:00 for $15 \mathrm{~min}, 5 \mathrm{~mL}$ black tea (Lipton, Unilever, İstanbul, Turkey) (pH 6.04) at 15:00 for $15 \mathrm{~min}$, and $5 \mathrm{~mL}$ of an alcohol-free mouth rinse (Listerine Total Care Zero, Johnson and Johnson, İstanbul, Turkey) (pH 4.48) at 18:00 for $30 \mathrm{~s}$, respectively, on the same day. After immersion in each beverage, the samples were rinsed with distilled water and then were kept in artificial saliva at $37^{\circ} \mathrm{C}$ in an incubator to mimic human oral conditions until the point of immersion in the subsequent liquid. This procedure was repeated for 30 days and each liquid was renewed every day. During the experiment, the flasks were covered to prevent evaporation of the solutions.

The artificial saliva was prepared in the Biochemistry Department of İstanbul University (İstanbul, Turkey) using the formula suggested by Shannon [16]. The composition of the artificial saliva was $4.2 \mathrm{mg} / \mathrm{L} \mathrm{NaF}, 1280 \mathrm{mg} / \mathrm{L} \mathrm{NaCl}$, $166.49 \mathrm{mg} / \mathrm{L} \mathrm{CaCl} 2,125 \mathrm{mg} / \mathrm{L} \mathrm{MgCl} 2.6 \mathrm{H}_{2} \mathrm{O}, 44.74 \mathrm{mg} / \mathrm{L} \mathrm{KCl}, 7.5 \mathrm{mg} / \mathrm{L} \mathrm{CH} \mathrm{COOK}_{3}, 386 \mathrm{mg} / \mathrm{L} \mathrm{K}{ }_{3} \mathrm{PO}_{4} .3 \mathrm{H}_{2} \mathrm{O}, 0.05 \mathrm{mg} / \mathrm{L}$ $\mathrm{H}_{3} \mathrm{PO}_{4}(85 \%)(\mathrm{pH} \mathrm{7})$.

\section{Color Measurement}

Before immersion in the beverages, the initial color measurements of all samples were performed using a spectrophotometer (Vita Easyshade Advance, VITA Zahnfabrik, Bad Säckingen, Germany). Subsequent color measurements were taken at the ends of days 1, 14, and 30 of immersion in the liquids.

Before the measurements, the spectrophotometer was calibrated according to the manufacturer's instructions. Each specimen was removed from the artificial saliva, rinsed with distilled water, and dried with an absorbent paper. Three measurements were conducted at the center of each specimen against a white background and the mean value was calculated. Color alterations were determined using the Commission Internationale d'Eclairge $\mathrm{L}^{*} \mathrm{a}{ }^{*} \mathrm{~b}^{*}$ color system (CIE L*a*b*). The CIE $\mathrm{L}^{*} \mathrm{a} \mathrm{b}^{*}$ color system is a three-dimensional color measurement system, where $\mathrm{L}^{*}$ is the lightness coordinate, and $\mathrm{a}^{*}$ and $\mathrm{b}^{*}$ are the chromacity coordinates in the red-green axis and the yellow-blue axis, respectively [17]. Color alteration values $(\Delta \mathrm{E})$ between initial and at the end of 1,14 , and 30 days were computed from the mean $\Delta \mathrm{L}, \Delta \mathrm{a}$, and $\Delta \mathrm{b}$ values for each sample with the subsequent formula $[1,18]$ :

$$
\Delta \mathrm{E}=\left[(\Delta \mathrm{L})^{2}+(\Delta \mathrm{a})^{2}+(\Delta \mathrm{b})^{2}\right]^{1 / 2}
$$

According to this formula, $\Delta \mathrm{L}, \Delta \mathrm{a}$, and $\Delta \mathrm{b}$ are the variations in the $\mathrm{L}$, $\mathrm{a}$, and $\mathrm{b}$ values, respectively, at baseline and after immersion at each time interval $(1,14$, and 30 days).

To determine the relationship between the amount of color alteration recorded on a spectrophotometer to the clinical environment, data were converted to the National Bureau of Standards (NBS) system (Table 2) [19, 20]. According to this system, $\Delta \mathrm{E}$ values can be described by the subsequent equation $[19,20]$ : NBS unit $=\Delta \mathrm{E} \times 0.92$.

Table 2. National Bureau of Standards (NBS) system of expressing color differences [19,20].

\begin{tabular}{|c|c|}
\hline$\Delta \mathbf{E}$ & NBS Criteria \\
\hline $0-0.5$ & Trace: Remarkably slight alteration \\
\hline $0.5-1.5$ & Slight: slight alteration \\
\hline $1.5-3$ & Noticeable: Observable alteration \\
\hline $3-6$ & Appreciable: Apparent alteration \\
\hline $6-12$ & Much: Remarkably apparent alteration \\
\hline 12 or more & Very much: Alteration to other color \\
\hline
\end{tabular}

NBS unit $=\Delta \mathrm{E} \times 0.92$ 


\section{Statistical Analysis}

Statistical analyses were done using SPSS version 22.0. All data were firstly analyzed by the Shapiro-Wilk test. One-way ANOVA and Tukey HSD tests were done to assess color changes of all materials between days of measurement. Repeated-measures ANOVA and post-hoc Bonferroni tests were executed to compare the color change of each material on different days $(P<0.05)$.

\section{RESULTS}

The results of the statistical analyses of color change values are presented in Table 3. According to one-way ANOVA and the Tukey HSD test, after the first day, Beautifil II showed a significantly higher color change than the Filtek Z250 and Voco x-tra Base materials; in addition, Beautiful Flow Plus showed a higher color change than Filtek Z250 $(P<0.05)$. However, no noteworthy color changes were observed between Filtek Z250 and Voco x-tra Base, Voco x-tra Base, and Beautiful Flow Plus, or between Beautiful Flow Plus and Beautiful II. At the $14^{\text {th }}$ day, Beautiful Flow Plus and Beautiful II showed higher color changes than the other materials $(P<0.05)$. Furthermore, Beautiful II showed a higher color change than Beautiful Flow Plus $(P<0.0001)$. However, no important difference was observed between Filtek Z250 and Voco x-tra Base. At the end of the $30^{\text {th }}$ day, Beautiful II showed the highest color change of all materials, and Beautiful Flow Plus and Voco X-tra Base showed higher color changes than Filtek Z250 $(P<0.0001)$. However, no significant color alteration was detected between Beautiful Flow Plus and Voco X-tra Base.

The results of repeated-measures ANOVA showed significant color changes in each material after 1, 14, and 30 days $(P<0.01)$. For each material, the lowest color alteration was detected after the first day, and the highest color alteration was detected after the $30^{\text {th }}$ day of storage.

According to the NBS system (Table 2), slight color change in Filtek Z250, noticeable color change in Beautifil Flow Plus/Voco x-tra Base, and appreciable color change in Beautifil II specimens were observed at the end of the first day. At the end of the $14^{\text {th }}$ day, much color alteration was observed in Filtek Z250 and Voco X-tra Base, and very much color alteration was observed in Beautifil Flow Plus and Beautifil II specimens. At the end of the $30^{\text {th }}$ day, all of the restorative materials showed very much color changes.

Table 3. Mean and standard deviation of color alteration values $(\Delta E)$ of restorative materials at 1,14 , and 30 days of daily immersion in various liquids.

\begin{tabular}{|c|c|c|c|c|c|}
\hline & \multicolumn{4}{|c|}{ Mean \pm SD } & \multirow{2}{*}{$P^{1}$} \\
\hline & Filtek Z250 & Voco x-tra Base & Beautifil Flow Plus & Beautifil II & \\
\hline 1 day & $1.17 \pm 0.6^{\mathrm{a}, \mathrm{A}}$ & $1.81 \pm 1.29^{\mathrm{ab}, \mathrm{A}}$ & $2.39 \pm 1.04^{\mathrm{bc}, \mathrm{A}}$ & $3.01 \pm 0.36^{\mathrm{c}, \boldsymbol{A}}$ & 0.001 \\
\hline 14 days & $7.31 \pm 1.9^{\mathrm{a}, \mathrm{B}}$ & $8.73 \pm 1.38^{\mathrm{a}, \mathrm{B}}$ & $12.59 \pm 1.81^{\mathbf{b}, \mathbf{B}}$ & $18.05 \pm 3.78^{\mathrm{c}, \mathbf{B}}$ & 0.001 \\
\hline 30 days & $17.26 \pm 3.97^{\mathrm{a}, \mathrm{C}}$ & $25.95 \pm 2.56^{\mathrm{b}, \mathrm{C}}$ & $26.28 \pm 1.73^{\mathrm{b}, \mathrm{C}}$ & $35.18 \pm 2.65^{\mathrm{c}, \mathrm{C}}$ & 0.001 \\
\hline$P^{2}$ & 0.001 & 0.001 & 0.001 & 0.001 & \\
\hline
\end{tabular}

One-way ANOVA, ${ }^{2}$ Repeated-measures ANOVA.

Different small letters in the same rows and different capital letters in the same column show statistical importance $(P<0.05)$.

\section{DISCUSSION}

Some studies $[21,22]$ reported that color change of composite resin stored in water showed highest degree of the color change after $24 \mathrm{~h}$ and 7 days. On the other hand, Domingos et al. [14] reported that the most pronounced color change of composite was occurred after 30 days. In addition Uchimura et al. [23] reported that the color change of composite resin was changed up to day 14 and then it was stabilized, therefore they pointed out that 14 days could be used as a reference for color comparison. Based on the results of these studies [14, $21-23]$, in this study color stability of four different resin composites that were immersed in multiple liquids (coffee, orange/pomegranate juice, tea, and mouth rinse respectively) on the same day were investigated after a period of 1, 14, and 30 days. All of the liquids used in the study were selected as colorant agents due to their constant consumption in daily life. To simulate clinical conditions as much as possible, the specimens were immersed in artificial saliva between immersions in each of the liquids.

It was reported that water sorption induces a weaker bond between the resin matrix and filler particles, and the consequent micro-cracks or interfacial gaps produced between the matrix and filler enable for stain penetration and discoloration of composite restorations $[4,7,10,24,25]$. Therefore, composite resins that consist of higher amounts of resin matrix [7, 10], larger filler particles [26], and low concentration of filler particles [27] could have an increased 
tendency toward discoloration. In addition, the type of resin matrix has also been reported to play an important role in staining susceptibility [28, 29]. Triethylene glycol dimethacrylate (TEGDMA) consists of hydrophilic groups and thus shows a high predisposition to water sorption. Kalachandra et al. [24] reported that water uptake in bisphenol A glycol dimethacrylate (Bis-GMA)-originated composite resins increased in proportion with the amount of TEGDMA. On the other hand, ethoxylated bisphenol A glycol dimethacrylate (Bis-EMA) and urethane dimethacrylate (UDMA) are highly hydrophobic, showing low water sorption and solubility characteristics [30].

Similar to the findings of previous studies [4, 7, 10, 25 - 29], the results of this study demonstrated that the restorative material type influenced color changes, supporting the influence of resin matrix composition, amount of filler weight, filler type, and filler particle size on color change susceptibility. Therefore, our results rejected the first null hypothesis because the type of composite resin affected the color stability of restorative material. In this study, the lowest color alteration was detected in Filtek Z250, which is likely due to the fact that it has a more hydrophobic resin matrix structure (Bis EMA, UDMA), higher filler weight (82\%), and smaller filler particle size $(0.6 \mu \mathrm{m})$ than the other materials. On the other hand, at all days, Beautifil Flow Plus and Beautifil II showed higher color changes than Filtek $\mathrm{Z} 250(P<0.05)$. This is due likely to the fact that both of these composites consist of a hydrophilic resin matrix type (TEGDMA) and have a higher filler particle size $(0.8 \mu \mathrm{m})$ than Filtek Z250 (Table 1). In addition, the color difference between Filtek and Voco X-tra Base was only significant after 30 days, whereas the color difference between Beautifil Flow Plus and Beautifil II was significant after 14 days. These results further demonstrate that if the resin matrix of the restorative material consists of hydrophilic components, color alteration may occur earlier.

In contrast, Beautifil II showed higher color alteration than Beautifil Flow Plus. Beautifil II has a higher filler weight than Beautifil Flow Plus, but the two materials have the same filler particle size and hydrophilic resin matrix composition. Therefore, we consider that this difference might be due to the fact that the ytterbium trifluoride in Beautifil II induced more water sorption than Beautifil Flow Plus, which would lead to enhanced color alteration.

Similar to previous studies $[11,31,32]$, a spectrophotometer and the CIE L*a*b* coordinate system was used to assess the color alteration due to the advantages of repeatability, sensitivity, objectivity, and determination of small color changes. Several studies $[7,25,33,34]$ reported that $\Delta \mathrm{E}$ values equal to or greater than 3.3 were considered clinically appreciable and unacceptable. In addition, in this study, NBS criteria were used to determine the relationship between the amount of color alteration recorded on a spectrophotometer and the clinical environment. After 1 day, all of the composite materials showed clinically acceptable color changes. However, after 14 and 30 days, the color alteration of all composite materials was deemed to be unacceptable, with very much color changes $(\Delta \mathrm{E} \geq 12)$ noted at 30 days.

The second null hypothesis, that the total time of exposure does not have an important effect on the color change of the restorative materials, was also rejected. For each composite type, the lowest color alteration was observed after the $1^{\text {st }}$ day, and the highest color alteration was observed after the $30^{\text {th }}$ day. This finding was also in agreement with previous studies [5, 28, 33, 35]. Although the results of this study showed similarity to these studies [5, 28, 33, 35] results, this study differed from them that it presented the daily consumption of a patient in in vitro conditions and the methodology used was different.

There were some limitations in this study. Although all of the composites were polished with Sof-Lex discs, the effect of surface roughness on the color change of restorative materials was not evaluated. On the other hand, the samples were not brushed after the oral simulation process, which might have influenced the staining susceptibility of the composite resins. In future studies, the influence of surface roughness, brushing, and beverage pH on the color stability of the restorative materials should be investigated.

\section{CONCLUSION}

Color alteration of composite resins was influenced by the sort of composite (resin matrix type, filler weight, filler particle size, and filler type) and storage time.

With the exception of the first day of storage, the color changes of all the materials were clinically unacceptable.

Among the materials tested, Filtek Z250 showed the lowest color alteration and Beautifil II showed the highest color alteration.

In clinical practice when selecting an appropriate restorative material, the dentists should consider the drinking and oral hygiene habits of the patients and the factors that may affect the color stability of restorative materials. In addition, patients should also be informed about the staining potential of the restorations. 


\section{CONFLICT OF INTEREST}

The authors confirm that this article content has no conflict of interest.

\section{ACKNOWLEDGEMENTS}

The authors thank the statistician Ebru Osmanoğlu for statistical analysis. The authors do not have any financial interest in the companies whose materials were used in this study. This study was self-funded.

\section{REFERENCES}

[1] Nasim I, Neelakantan P, Sujeer R, Subbarao CV. Color stability of microfilled, microhybrid and nanocomposite resins--an in vitro study. J Dent 2010; 38(Suppl. 2): e137-42. [http://dx.doi.org/10.1016/j.jdent.2010.05.020] [PMID: 20553993]

[2] Ren YF, Feng L, Serban D, Malmstrom HS. Effects of common beverage colorants on color stability of dental composite resins: the utility of a thermocycling stain challenge model in vitro. J Dent 2012; 40(Suppl. 1): e48-56. [http://dx.doi.org/10.1016/j.jdent.2012.04.017] [PMID: 22542498]

[3] Asmussen E, Hansen EK. Surface discoloration of restorative resins in relation to surface softening and oral hygiene. Scand J Dent Res 1986; 94(2): 174-7.

[PMID: 2939546]

[4] Bagheri R, Burrow MF, Tyas M. Influence of food-simulating solutions and surface finish on susceptibility to staining of aesthetic restorative materials. J Dent 2005; 33(5): 389-98. [http://dx.doi.org/10.1016/j.jdent.2004.10.018] [PMID: 15833394]

[5] Ertaş E, Güler AU, Yücel AC, Köprülü H, Güler E. Color stability of resin composites after immersion in different drinks. Dent Mater J 2006; 25(2): 371-6.

[http://dx.doi.org/10.4012/dmj.25.371] [PMID: 16916243]

[6] Türkün LS, Türkün M. Effect of bleaching and repolishing procedures on coffee and tea stain removal from three anterior composite veneering materials. J Esthet Restor Dent 2004; 16(5): 290-301. [http://dx.doi.org/10.1111/j.1708-8240.2004.tb00056.x] [PMID: 15726798]

[7] Barutcigil Ç, Yıldız M. Intrinsic and extrinsic discoloration of dimethacrylate and silorane based composites. J Dent 2012; 40(Suppl. 1): e57-63. [http://dx.doi.org/10.1016/j.jdent.2011.12.017] [PMID: 22239912]

[8] Gregorius WC, Kattadiyil MT, Goodacre CJ, Roggenkamp CL, Powers JM, Paravina RD. Effects of ageing and staining on color of acrylic resin denture teeth. J Dent 2012; 40(Suppl. 2): e47-54.

[http://dx.doi.org/10.1016/j.jdent.2012.09.009] [PMID: 23007129]

[9] Villalta P, Lu H, Okte Z, Garcia-Godoy F, Powers JM. Effects of staining and bleaching on color change of dental composite resins. J Prosthet Dent 2006; 95(2): 137-42.

[http://dx.doi.org/10.1016/j.prosdent.2005.11.019] [PMID: 16473088]

[10] Ferracane JL, Berge HX, Condon JR. In vitro aging of dental composites in water--effect of degree of conversion, filler volume, and filler/matrix coupling. J Biomed Mater Res 1998; 42(3): 465-72. [http://dx.doi.org/10.1002/(SICI)1097-4636(19981205)42:3<465::AID-JBM17>3.0.CO;2-F] [PMID: 9788511]

[11] Erdemir U, Yildiz E, Eren MM. Effects of sports drinks on color stability of nanofilled and microhybrid composites after long-term immersion. J Dent 2012; 40(Suppl. 2): e55-63.

[http://dx.doi.org/10.1016/j.jdent.2012.06.002] [PMID: 22713737]

[12] Lepri CP, Palma-Dibb RG. Influence of surface sealant on the color-stability of a composite resin immersed in different beverages. Oral Health Dent Manag 2014; 13(3): 600-4. [PMID: 25284519]

[13] Tuncer D, Karaman E, Firat E. Does the temperature of beverages affect the surface roughness, hardness, and color stability of a composite resin? Eur J Dent 2013; 7(2): 165-71. [http://dx.doi.org/10.4103/1305-7456.110161] [PMID: 24883021]

[14] Domingos PA, Garcia PP, Oliveira AL, Palma-Dibb RG. Composite resin color stability: influence of light sources and immersion media. J Appl Oral Sci 2011; 19(3): 204-11.

[http://dx.doi.org/10.1590/S1678-77572011000300005] [PMID: 21625734]

[15] Topcu FT, Sahinkesen G, Yamanel K, Erdemir U, Oktay EA, Ersahan S. Influence of different drinks on the colour stability of dental resin composites. Eur J Dent 2009; 3(1): 50-6. [PMID: 19262731]

[16] Shannon IL. Fluoride treatment programs for high-caries-risk patients. Clin Prev Dent 1982; 4(2): 11-20. [PMID: 6980768]

[17] Dozić A, Kleverlaan CJ, El-Zohairy A, Feilzer AJ, Khashayar G. Performance of five commercially available tooth color-measuring devices. 
J Prosthodont 2007; 16(2): 93-100.

[http://dx.doi.org/10.1111/j.1532-849X.2007.00163.x] [PMID: 17362418]

[18] Gupta R, Parkash H, Shah N, Jain VA. Spectrophotometric evaluation of color changes of various tooth colored veneering materials. J Indian Prosthodont Soc 2005; 5: 72-8. [http://dx.doi.org/10.4103/0972-4052.16873]

[19] Ertan AA, Sahin E. Colour stability of low fusing porcelains: an in vitro study. J Oral Rehabil 2005; 32(5): $358-61$. [http://dx.doi.org/10.1111/j.1365-2842.2004.01415.x] [PMID: 15842245]

[20] Central Bureau of the International Commission on Illumination. Colorimetry. Vienna: CIE Publication 1986 ; p. 30.

[21] Sabatini C, Campillo M, Aref J. Color stability of ten resin-based restorative materials. J Esthet Restor Dent 2012; 24(3): 185-99. [http://dx.doi.org/10.1111/j.1708-8240.2011.00442.x] [PMID: 22691080]

[22] Buchalla W, Attin T, Hilgers RD, Hellwig E. The effect of water storage and light exposure on the color and translucency of a hybrid and a microfilled composite. J Prosthet Dent 2002; 87(3): 264-70. [http://dx.doi.org/10.1067/mpr.2002.121743] [PMID: 11941352]

[23] Uchimura JY, Sato F, Bianchi G, Baesso ML, Santana RG, Pascotto RC. Color stability over time of three resin-based restorative materials stored dry and in artificial saliva. J Esthet Restor Dent 2014; 26(4): 279-87. [http://dx.doi.org/10.1111/jerd.12106] [PMID: 24974906]

[24] Kalachandra S, Turner DT. Water sorption of polymethacrylate networks: bis-GMA/TEGDM copolymers. J Biomed Mater Res 1987; 21(3): 329-38. [http://dx.doi.org/10.1002/jbm.820210306] [PMID: 2951387]

[25] Soares-Geraldo D, Scaramucci T, Steagall-Jr W, Braga SR, Sobral MA. Interaction between staining and degradation of a composite resin in contact with colored foods. Braz Oral Res 2011; 25(4): 369-75. [http://dx.doi.org/10.1590/S1806-83242011000400015] [PMID: 21860925]

[26] Catelan A, Briso AL, Sundfeld RH, Goiato MC, dos Santos PH. Color stability of sealed composite resin restorative materials after ultraviolet artificial aging and immersion in staining solutions. J Prosthet Dent 2011; 105(4): 236-41. [http://dx.doi.org/10.1016/S0022-3913(11)60038-3] [PMID: 21458648]

[27] Schulze KA, Marshall SJ, Gansky SA, Marshall GW. Color stability and hardness in dental composites after accelerated aging. Dent Mater 2003; 19(7): 612-9. [http://dx.doi.org/10.1016/S0109-5641(03)00003-4] [PMID: 12901985]

[28] Inokoshi S, Burrow MF, Kataumi M, Yamada T, Takatsu T. Opacity and color changes of tooth-colored restorative materials. Oper Dent 1996; 21(2): 73-80. [PMID: 8957922]

[29] Khokhar ZA, Razzoog ME, Yaman P. Color stability of restorative resins. Quintessence Int 1991; $22(9)$ : $733-7$. [PMID: 1946950]

[30] Peutzfeldt A. Resin composites in dentistry: the monomer systems. Eur J Oral Sci 1997; 105(2): 97-116 [http://dx.doi.org/10.1111/j.1600-0722.1997.tb00188.x] [PMID: 9151062]

[31] Mundim FM, Garcia LdaF, Pires-de-Souza FdeC. Effect of staining solutions and repolishing on color stability of direct composites. J Appl Oral Sci 2010; 18(3): 249-54.

[http://dx.doi.org/10.1590/S1678-77572010000300009] [PMID: 20857002]

[32] Brook AH, Smith RN, Lath DJ. The clinical measurement of tooth colour and stain. Int Dent J 2007; 57(5): 324-30. [http://dx.doi.org/10.1111/j.1875-595X.2007.tb00141.x] [PMID: 17992918]

[33] Yazici AR, Celik C, Dayangaç B, Ozgünaltay G. The effect of curing units and staining solutions on the color stability of resin composites. Oper Dent 2007; 32(6): 616-22.

[http://dx.doi.org/10.2341/07-3] [PMID: 18051013]

[34] Vichi A, Ferrari M, Davidson CL. Color and opacity variations in three different resin-based composite products after water aging. Dent Mater 2004; 20(6): 530-4. [http://dx.doi.org/10.1016/j.dental.2002.11.001] [PMID: 15134940]

[35] Samra AP, Pereira SK, Delgado LC, Borges CP. Color stability evaluation of aesthetic restorative materials. Braz Oral Res 2008; 22(3): 205-10.

[http://dx.doi.org/10.1590/S1806-83242008000300003] [PMID: 18949304]

(C) Özdaş et al.; Licensee Bentham Open

This is an open access article licensed under the terms of the Creative Commons Attribution-Non-Commercial 4.0 International Public License (CC BY-NC 4.0) (https://creativecommons.org/licenses/by-nc/4.0/legalcode), which permits unrestricted, non-commercial use, distribution and reproduction in any medium, provided the work is properly cited. 